\title{
Regulação no Brasil: desenho das agências e formas de controle*
}

\author{
Regina Silvia Pacheco**
}

S U MÁRIO: 1. Introdução; 2. A reforma de 1995 e as "agências autônomas"; 3. Processo de criação das agências reguladoras; 4. Um modelo único para a infra-estrutura e a área social; 5. ...com pequenas variações; 6. Propostas para alterar o modelo; 7. Referência: o modelo americano; 8. As diferentes formas de controle; 9. Algumas conclusões.

SUMMARY: 1. Introduction; 2. The 1995 reform and the 'autonomous agencies'; 3. Creation process of the regulatory agencies; 4 . One model for the infrastructure and the social area; 5 . ...with slight variations; 6. Model modification proposals; 7. Standard: the American model; 8. The different forms of control; 9. A few conclusions.

PAlavRAS-CHAVE: Brasil: agências reguladoras; credibilidade regulatória; controle político; controle hierárquico.

KEY WORDS: Brazil: regulatory agencies; regulatory credibility; political control; hierarchical control.

Este artigo discute a gênese das agências reguladoras (ARs) no Brasil, as propostas para revisão do modelo e as distintas formas de controle sobre estes novos entes, dotados de autonomia. No processo de criação das ARs, entre 1996 e 2002, o modelo adotado para a área de infra-estrutura foi indevidamente estendido às demais agências. Tal inadequação não foi corrigida nas propostas de revisão do modelo, encaminhadas pelo novo governo ao Congresso. Após fazer as distinções necessárias entre a experiência dos EUA e o contexto brasileiro, o artigo recupera, da experiência norte-ameri-

* Artigo recebido em fev. e aceito em maio 2006.

** Doutora pela Universidade de Paris XII. Professora-adjunta do Programa de Mestrado e Doutorado em Administração Pública e Governo da Eaesp/FGV. Endereço: Av. Nove de Julho, 2029 — Bela Vista — CEP 01313-902, São Paulo, SP, Brasil. E-mail: rpacheco@fgvsp.br. 
cana, a distinção entre várias formas de controle (hierárquico, político e social). No Brasil, no debate sobre o grau de autonomia das ARs são confundidas as formas de controle, muito freqüentemente denominando "controle político" aquilo que é de fato controle hierárquico, e "controle social" como sinônimo de controle político. Para a autora, não há antinomia entre independência da agência e controle político, mas sim entre controle hierárquico e independência; também não é apropriado confundir controle social e controle político. A criação das agências sob um modelo único e a indistinção entre as formas de controle podem ser explicadas pela combinação de características do sistema político-institucional brasileiro, com preferências e resistências de atores intragovernamentais - especialmente do Executivo federal.

\section{Regulation in Brazil: agency design and control forms}

This article discusses the genesis of the regulatory agencies (RAs) in Brazil, the model modification proposals and the different forms of control over these new entities. During the RA creation process, between 1996 and 2002, the infrastructure sector model was improperly extended to the other agencies. This inadequacy was not corrected by the model reviews proposed to Congress by the new government. After comparing the American and the Brazilian contexts, the article retrieves from the American experience the differences between the forms of control: hierarchical, political, and social. In Brazil, in the discussion about the extent of AR autonomy the forms of control are confused, and very often what is called 'political control' is in fact hierarchical control, and 'social control' is a synonym for political control. The author believes that agency independence and political control are not antonymous, but hierarchical control and independence are. It is also wrong to confuse social control and political control. Agency creation under a single model and indistinction between control forms can be explained by the combination of characteristics of the Brazilian institutional-political system, with preferences and resistances by actors within the government, especially from the federal Executive branch.

\section{Introdução}

Este artigo discute a gênese das agências reguladoras no Brasil, criadas a partir do final dos anos 1990, o processo de revisão do modelo inicialmente adotado e o debate em torno do controle $x$ autonomia das agências. Quanto à criação das agências, é apontada a falta de distinção entre as voltadas à infraestrutura e à área social. Retomamos duas teses, já apresentadas por outros autores: a primeira sustenta que o modelo de agência reguladora da área de infra-estrutura foi indevidamente estendido às demais agências (Salgado, 
2003); a segunda tese afirma que esta extensão indevida pode ser explicada pelas dificuldades encontradas, dentro do próprio governo, pelo modelo de "agências executivas" (Costa, 2002). Atualizando o debate, procuramos mostrar que o assunto continua pendente, não tendo sido tocado nas discussões recentes sobre a revisão do modelo institucional de agências reguladoras, suscitadas a partir de 2003.

As agências reguladoras federais foram criadas a partir de 1996, inspiradas pela experiência internacional, como entes públicos dotados de independência em relação ao Poder Executivo. Com a mudança de governo em 2003, presidente e ministros de Estado passaram a questionar o desenho adotado, o que deu início a um debate sobre o grau de autonomia dessas entidades. A iniciativa do Poder Executivo resultou no envio de um projeto de lei ao Congresso, em abril de 2004, propondo importantes alterações no modelo anterior. Este projeto uniformiza ainda mais o desenho das agências reguladoras existentes.

Cabe ressaltar que a maioria dos autores brasileiros dedicados ao tema da regulação tem, como principal referência, a literatura sobre os EUA. No entanto, nos EUA o debate é fortemente marcado pela experiência pré e pósNew Deal e por resistências à ampliação da intervenção do Estado, especialmente do Executivo federal. No Brasil, a criação das agências independentes teve outros fundamentos além da necessidade de delegação do Executivo para criar credibilidade regulatória; as razões para criação de algumas agências parecem envolver a tentativa de escapar à rigidez do modelo burocrático consagrado pela Constituição de 1988.

Assim, interessa notar que, no caso americano, o debate se travou sobre mais ou menos Estado, enquanto no Brasil a criação das agências reguladoras independentes remete ao debate sobre mais ou menos governo (ou mais ou menos política) e ainda sobre mais ou menos burocracia (e controles burocráticos). Por outro lado, é útil retomar o caso dos EUA quanto às formas de controle que promovem maior accountability dos entes reguladores, sem colocar em risco seu principal atributo - a autonomia, que inclui, segundo a ênfase deste artigo, a eqüidistância dos atores governamentais.

\section{A reforma de 1995 e as "agências autônomas"}

Em 1995, o governo federal propôs um amplo programa de reformas, elaborado pelo ministro Luiz Carlos Bresser-Pereira e sua equipe no Ministério da Administração Federal e Reforma do Estado (Mare), então recém-criado. Suas propostas principais visavam a descentralização da prestação de servi- 
ços públicos (para esferas subnacionais e para o setor público não-estatal) e ao fortalecimento do núcleo estratégico do Estado - responsável pela formulação das políticas públicas e pelas novas funções de regulação.

A reforma do Estado deve ser entendida dentro do contexto da redefinição do papel do Estado, que deixa de ser o responsável direto pelo desenvolvimento econômico e social pela via da produção de bens e serviços, para fortalecer-se na função de promotor e regulador desse desenvolvimento. (...) Busca-se o fortalecimento das funções de regulação e de coordenação do Estado, particularmente no nível federal, e a progressiva descentralização vertical, para os níveis estadual e municipal, das funções executivas no campo da prestação de serviços sociais e infraestrutura.

(Brasil, 1995, destaques da autora)

Apesar da referência à função de regulação, o Plano Diretor da Reforma do Aparelho do Estado (Pdrae) não apresentou proposta específica para a criação de entes regulatórios. Englobou-os, junto com as demais atividades exclusivas do Estado, dentro da proposta de "agências autônomas", que deveriam ter maior autonomia para atingir melhores resultados. $\mathrm{O}$ foco era o da superação da rigidez burocrática, que desde a Constituição de 1988 amarrou a administração indireta aos mesmos controles formais da administração direta.

Quando o Plano Diretor foi elaborado, no início de 1995, o debate sobre regulação não havia ainda sido iniciado; o Congresso discutia as primeiras emendas constitucionais que quebravam monopólios estatais. Segundo Farias (2002:95-96), um dos integrantes da equipe do Mare,

\footnotetext{
podemos dizer que a percepção clara de que a questão da regulação tinha um peso diferenciado veio no final de 1995, quando a sociedade começou a dar-se conta de que a concorrência e a qualidade do processo regulatório interferiam diretamente em variáveis do seu dia-a-dia, tais como o nível de emprego, a qualidade e a oferta de bens e serviços públicos.
}

O tema foi mais tarde discutido por Bresser-Pereira em um livro publicado em 1998. Quando trata das agências executivas, o autor aponta semelhanças entre elas e as agências reguladoras: ambas devem ser dotadas de maior autonomia de gestão (ou autonomia administrativa). No entanto, o autor considera que as agências reguladoras devam ser mais autônomas em relação ao governo, pois sua autonomia deriva do fato de executarem políticas permanentes de Estado - regular preços de serviços públicos monopolistas, determinan- 
do o preço que seria o de mercado se mercado houvesse (Bresser-Pereira, 1998:225-227). Ainda entre as diferenças, Bresser-Pereira considera que o contrato de gestão apenas é devido no caso das agências executivas, e o mandato fixo de dirigentes às agências reguladoras: "Seus dirigentes (das ARs) são detentores de mandato e têm sua indicação aprovada pelo Congresso, o que não acontece com os dirigentes das agências executivas, que são de livre nomeação e exoneração pelo presidente da República" (Bresser-Pereira, 1998:226).

Dessa forma, Bresser-Pereira distingue claramente autonomia administrativa (voltada à eficiência e aos resultados) de autonomia política (voltada à continuidade e credibilidade decisória). O paradigma gerencial justificava a ampliação da autonomia administrativa para ambos os tipos de agência, executiva e reguladora; já a autonomia política deveria ser reservada às agências reguladoras, por atuarem em áreas monopolistas, característica dos setores de infra-estrutura - telecomunicações, energia e petróleo.

$\mathrm{O}$ autor das propostas de reforma considera, portanto, que há diferenças fundamentais entre os dois formatos organizacionais, agências reguladoras ou executivas, que têm por base a natureza distinta das funções de cada uma. Tais argumentos foram formulados depois da elaboração do Plano Diretor, no momento em que haviam sido criadas apenas três agências, todas na área de infra-estrutura (Anatel, Aneel e $\left.\mathrm{ANP}^{1}\right)^{2}{ }^{2}$

\section{Processo de criação das agências reguladoras}

Na maioria dos setores de infra-estrutura, a criação de agências para regular e fiscalizar os novos agentes privados deu-se no final da década de 1990, após a privatização. ${ }^{3}$ Dessa forma, a criação do marco regulatório vem sendo posterior à privatização, o que tem sido objeto de críticas e talvez responsável por várias das dificuldades em curso. ${ }^{4}$

\footnotetext{
${ }^{1} \mathrm{O}$ autor inclui ainda, como agências reguladoras existentes, o Banco Central e o Cade. Formalmente, no entanto, apenas são consideradas agências reguladoras, na administração pública federal, os órgãos onde há remissão expressa ao termo em sua lei de criação.

${ }^{2}$ A Casa Civil já discutia, à época, o projeto das duas agências da área da saúde, cuja justificativa escapa à lógica dos argumentos expostos por Bresser-Pereira.

${ }^{3}$ A única exceção coube ao setor de telecomunicações, onde a criação do marco regulatório e da agência reguladora antecederam a privatização.

${ }^{4}$ Segundo Armando Castelar, economista do Ipea, o sucesso dos investimentos em telecomunicações aconteceu porque o setor tinha marco regulatório e agência reguladora (Anatel) com poder de decisão e tarifas corrigidas em patamares internacionais antes mesmo do leilão que vendeu a Telebrás. O contrário aconteceu com o setor elétrico, cuja regulação e criação da agência reguladora (Aneel) só aconteceu muito depois do início das privatizações do setor (Valor Online, 4 ago. 2003).
} 
A criação das agências reguladoras não teve o Mare como lócus de elaboração, e sim a Casa Civil (Costa, 2002). O primeiro projeto de criação de uma agência reguladora - Aneel, do setor de energia elétrica - foi enviado pelo Executivo federal ao Congresso no final de 1995, sob o modelo de autarquia convencional - sem autonomia decisória nem os demais requisitos de estrutura e procedimentos que caracterizam as agências reguladoras. Coube ao Congresso a iniciativa de questionamento do modelo tradicional e a busca de modelos alternativos, a partir da experiência internacional. Segundo Farias (2002:96), participante do processo de criação daquela primeira agência pelo Executivo, "nesse caso, o Congresso Nacional assumiu uma posição de vanguarda, forçando o Executivo a avançar em alguns pontos e incorporando idéias que não estavam colocadas no projeto original". Assim, apesar de a iniciativa da lei ter sido do Poder Executivo, poderíamos considerar que coube ao Poder Legislativo trazer para a agenda a discussão do grau de autonomia desejável para os novos entes reguladores.

Outro ator relevante foi o Conselho da Reforma do Estado, órgão de assessoria ao presidente da República, formado por intelectuais e notáveis. Em sua primeira resolução, adotada no início de 1996, o Conselho da Reforma do Estado sugeria critérios e princípios a serem adotados pelo marco regulatório e para a criação das novas entidades reguladoras, entre eles a autonomia e independência decisória do ente regulador por meio de mandatos fixos para os dirigentes e não coincidentes com os do Executivo; a decisão colegiada precedida de ampla e prévia consulta pública sobre as normas a serem editadas, junto ao setor regulado e aos usuários; a agilidade processual; o estabelecimento de níveis desejáveis de prestação do serviço (Abranches, 1999).

Dessa forma, as principais arenas de discussão parecem ter sido externas à burocracia do Executivo - sendo a exceção, mais uma vez, o setor de telecomunicações. Ali, o ex-ministro Sergio Motta teria tido papel protagonista no desenho da agência reguladora, a partir de estudos sobre a experiência internacional comandados por ele, logo que assumiu o Ministério das Comunicações. ${ }^{5}$

\footnotetext{
${ }^{5}$ Segundo Siqueira (2002:219), "sua primeira preocupação [de Sergio Motta, empossado ministro das Comunicações em 2-1-1995] foi fazer o grande diagnóstico setorial e conhecer o que havia de melhor no mundo em matéria de legislação e modelos institucionais de telecomunicações. Nesse sentido, dois meses depois de sua posse, ele encarregou três assessores de viajar à Europa, aos EUA e ao Japão para fazer um levantamento das principais legislações existentes nessas regiões do mundo".
} 
O debate no Legislativo se estendeu por mais de um ano, sendo a primeira agência criada no final de 1996, segundo o formato consagrado na experiência internacional: autonomia decisória e financeira, mandatos fixos para seus dirigentes e não coincidentes com os do chefe do Executivo. Os demais projetos incorporaram tal modelo já em sua proposta inicial.

\begin{tabular}{|c|c|c|}
\hline \multicolumn{3}{|c|}{ Criação das agências reguladoras na esfera federal } \\
\hline Agência & Lei & Ministério supervisor \\
\hline $\begin{array}{l}\text { Agência Nacional de Energia } \\
\text { Elétrica (Aneel) }\end{array}$ & $\begin{array}{l}\text { Lei } n^{0} 9.427 \text {, de } 26 \text { de dezembro } \\
\text { de } 1996\end{array}$ & $\begin{array}{l}\text { Ministério das Minas e Energia } \\
\text { (MME) }\end{array}$ \\
\hline $\begin{array}{l}\text { Agência Nacional de } \\
\text { Telecomunicações (Anatel) }\end{array}$ & $\begin{array}{l}\text { Lei } n^{0} 9.472 \text {, de } 16 \text { de julho } \\
\text { de } 1997\end{array}$ & Ministério das Comunicações (MC) \\
\hline $\begin{array}{l}\text { Agência Nacional de } \\
\text { Petróleo (ANP) }\end{array}$ & $\begin{array}{l}\text { Lei } n^{0} 9.478 \text {, de } 6 \text { de agosto } \\
\text { de } 1997\end{array}$ & $\begin{array}{l}\text { Ministério das Minas e Energia } \\
\text { (MME) }\end{array}$ \\
\hline $\begin{array}{l}\text { Agência Nacional de Vigilância } \\
\text { Sanitária (Anvisa) }\end{array}$ & $\begin{array}{l}\text { Lei } n^{0} 9.782 \text {, de } 26 \text { de janeiro } \\
\text { de } 1999\end{array}$ & Ministério da Saúde (MS) \\
\hline $\begin{array}{l}\text { Agência Nacional de Saúde } \\
\text { Suplementar (ANS) }\end{array}$ & $\begin{array}{l}\text { Lei } n^{0} 9.961 \text {, de } 28 \text { de janeiro } \\
\text { de } 2000\end{array}$ & Ministério da Saúde (MS) \\
\hline $\begin{array}{l}\text { Agência Nacional de } \\
\text { Águas (ANA) }\end{array}$ & $\begin{array}{l}\text { Lei } n^{0} 9.984 \text {, de } 17 \text { de julho } \\
\text { de } 2000\end{array}$ & $\begin{array}{l}\text { Ministério do Meio Ambiente } \\
\text { (MMA) }\end{array}$ \\
\hline $\begin{array}{l}\text { Agência Nacional de Transportes } \\
\text { Aquaviários (Antaq) }\end{array}$ & $\begin{array}{l}\text { Lei } n^{0} 10.233 \text {, de } 5 \text { de junho } \\
\text { de } 2001\end{array}$ & Ministério dos Transportes (MT) \\
\hline $\begin{array}{l}\text { Agência Nacional de Transporte } \\
\text { Terrestre (ANTT) }\end{array}$ & $\begin{array}{l}\text { Lei } n^{0} 10.233 \text {, de } 5 \text { de junho } \\
\text { de } 2001\end{array}$ & Ministério dos Transportes (MT) \\
\hline $\begin{array}{l}\text { Agência Nacional do Cinema } \\
\text { (Ancine) }\end{array}$ & $\begin{array}{l}\text { Estabelecida pela MP } n^{0}-2.228 \text {, } \\
\text { de } 6 \text { de setembro de } 2001\end{array}$ & Casa Civil \\
\hline $\begin{array}{l}\text { Agência Nacional de Aviação } \\
\text { Civil (Anac) }\end{array}$ & $\begin{array}{l}\text { Lei } n^{0} 11.182 \text {, de } 27 \text { de } \\
\text { setembro de } 2005\end{array}$ & Ministério da Defesa \\
\hline
\end{tabular}

Entre as agências criadas, o caso da Ancine é bastante peculiar. ${ }^{6}$ Definida como "órgão de fomento, regulação e fiscalização da indústria cinematográfica e videofonográfica", suas atribuições parecem caracterizar a

${ }^{6}$ Ver Costa (2002). 
atividade de fomento, mais do que regulação. Não se justifica, portanto, o formato de agência reguladora. Foi a única agência reguladora criada por medida provisória. Sua vinculação inicial foi à Casa Civil, com previsão de posterior vinculação ao Ministério do Desenvolvimento, Indústria e Comércio Exterior. ${ }^{7}$

Pesquisadores brasileiros começaram a publicar artigos sobre o tema das agências reguladoras a partir de 1998/99. Inicialmente, maior ênfase foi dada às áreas de infra-estrutura e aos aspectos econômicos da regulação: características do setor, instrumentos da regulação, mecanismos tarifários, entre outros (Pires e Piccini, 1999). A análise dos aspectos político-institucionais da regulação é ainda mais recente; seus autores discutem os desafios para o avanço da regulação no Brasil, em razão das características de seu sistema político e institucional (Peci e Cavalcanti, 2000; Melo, 2000, 2001, 2002; Mueller e Pereira, 2002).

Entre as razões apontadas para a criação de entes reguladores independentes no Brasil, vários autores distinguem agências da infra-estrutura e da área social. No setor de infra-estrutura, diversos autores tendem a convergir em torno de argumentos que privilegiam a busca de credibilidade regulatória, além da necessária especialização técnica (Mueller e Pereira, 2002; Melo, 2000, 2001 e 2002). Para explicar as agências reguladoras na área social, alguns autores recorrem ao blame shifting - a criação de tais agências representaria uma tentativa, por parte do governo, de se desonerar de decisões muitas vezes complexas e impopulares (Melo, 2002).

Um interessante exemplo pode ser visto em Mueller e Pereira (2002): os autores modelam a tese da credibilidade regulatória e aplicam-na à criação das agências no Brasil. Segundo o modelo, o grau de autonomia das diferentes agências deveria variar segundo características do setor regulado. No entanto, quando examinaram as evidências empíricas, os autores não encontraram tais variações entre as agências criadas, apesar das notáveis diferenças nos mercados a que se dirigem. Como conclusão, os autores consideram que o modelo está correto (apesar de não confirmado pelas evidências), e que o descompasso entre o modelo e a realidade deve-se não a falhas do modelo, mas ao fato de se tratar de uma experiência recente, ainda em evolução - "a realidade deve evoluir de acordo com os pressupostos do modelo".

\footnotetext{
${ }^{7}$ Apenas em outubro de 2003 a Ancine passou a ser vinculada ao Ministério da Cultura, por meio do Decreto nํㅜ 4.858, de 13 de outubro de 2003. 


\section{Um modelo único para a infra-estrutura e a área social}

Observando o conjunto de agências reguladoras criadas a partir de 1997, alguns autores consideram que o modelo de agência reguladora da área de infra-estrutura foi expandido para outros setores, indevidamente (Costa, 2002; Salgado, 2003). Nas áreas de infra-estrutura, que muitas vezes constituem monopólios naturais, justifica-se com mais clareza a adoção dos requisitos de autonomia e desvinculação política da agência em relação ao governo, diante da longa maturação dos altos investimentos requeridos, dos requisitos tecnológicos e da decorrente necessidade de assegurar regras estáveis para atrair investidores privados.

Assim, configura-se, nesses casos, a natureza complexa da atividade reguladora, cuja finalidade é buscar equilibrar as perspectivas dos investidores, do governo e dos usuários desses serviços. Nos setores de infra-estrutura, a regulação visa promover a universalização do acesso aos serviços e a competição em áreas de monopólios naturais, corrigindo falhas de mercado.

Já na área social, a regulação abrange os direitos dos usuários e a qualidade dos serviços. A natureza das atividades parece indicar muito mais uma atuação fiscalizadora do Estado, do que propriamente a regulação de mercados ou a promoção da concorrência; em geral, nessas áreas a existência de um mercado precede a criação da agência. Ainda assim, a necessidade de regulação se justifica dadas as falhas de mercado relativas à forte assimetria de informação (pró-firmas), às externalidades negativas, ao risco moral e à seleção adversa.

A literatura aponta que, na área social, a necessidade de regulação não implica a necessidade de agências reguladoras independentes. Aqui, não se trata de garantir ou simular a concorrência, como se mercado houvesse, mas sim ordenar o mercado e a competição para que não ponham em risco os direitos dos usuários dos serviços - tarefa que pode ser atribuída simultaneamente ao órgão de defesa da concorrência e a uma agência da administração indireta que fiscalize a qualidade dos serviços efetivamente prestados e o respeito aos direitos dos usuários.

Apesar das distinções presentes na literatura, o mesmo modelo organizacional foi adotado, no Brasil, tanto para a área de infra-estrutura quanto

para a área social, concedendo autonomia às agências de ambas as áreas e desvinculando mandatos de seus dirigentes daqueles do chefe de governo.

Segundo o Plano Diretor, o formato mais adequado para as entidades voltadas à fiscalização e ao fomento seria o das agências executivas, inspiradas na experiência inglesa das agencies. Suas atribuições implicam o exercício de poder de Estado, o que justifica sua manutenção como "atividades 
exclusivas de Estado", não devendo ser repassadas ao setor privado nem ao setor público não-estatal (Brasil, 1995). Por outro lado, o melhor desempenho de suas competências requer flexibilidades na gestão, como aquelas previstas no modelo de agências executivas, em troca de compromisso prévio com resultados, firmado por meio de um contrato de gestão.

A pouca disposição do "núcleo duro do governo", 8 durante o governo FHC, em conceder as autonomias requeridas ao bom funcionamento das agências executivas, talvez explique sua baixa implementação - há apenas uma agência executiva federal, o Instituto Nacional de Metrologia (Inmetro). ${ }^{9}$

Nesse contexto, alguns ministérios setoriais e suas entidades vinculadas não aderiram à proposta de "agência executiva"; preferiram pleitear a criação de agência reguladora, dotada de maior autonomia quanto à gestão de recursos humanos, maior flexibilidade na execução orçamentária e nas compras, entre outras. Este teria sido o caso das agências reguladoras da área social, segundo Costa (2002).

Parece-nos que os argumentos de Costa apresentam maior pertinência do que aqueles que remetem ao blame shifting, para explicar a criação de agências reguladoras da área social. ${ }^{10}$ A ANS e Anvisa foram criadas com o forte empenho do então ministro da Saúde, José Serra. Seu empenho na criação das duas agências, sob o formato de agências reguladoras, parece ser mais atribuível à busca de autonomia para alavancar o desempenho institucional, do que à tentativa de blame shifting. ${ }^{11}$

Mas as indefinições do governo (quanto às agências executivas) e as preferências das entidades (por maior autonomia) e de ministros (por resultados em suas áreas de responsabilidade) poderiam levar a um desvirtuamento do modelo de agência reguladora - ao estendê-lo a setores onde não é imprescindível (Salgado, 2003). Este aspecto, como veremos adiante, poderia ter sido revisto pelo novo governo a partir de 2003, mas não o foi. O projeto de lei que altera dispositivos da legislação criada no governo anterior, além de manter as agências reguladoras existentes, promove ainda maior uniformização institucional entre elas.

\footnotetext{
${ }^{8}$ Compreendido pelas áreas econômica, jurídica e de assessoria direta ao presidente (Casa Civil).

${ }^{9}$ Para a área econômica, comprometida com a garantia dos fundamentos macroeconômicos, a prioridade era o ajuste fiscal. Muitos de seus integrantes receiam que a concessão de maiores flexibilidades de gestão implique aumento do gasto público, colocando em risco o esforço de ajuste.

${ }^{10}$ Também chamadas de "agências de segunda geração".

11 Vigilância Sanitária era atribuição de uma secretaria do Ministério da Saúde — administração direta.
} 


\section{5. ...com pequenas variações}

Apesar de Mueller e Pereira (2002) terem considerado não haver variações entre as agências reguladoras criadas no Brasil, uma análise mais recente, de Gelis Filho (2004), buscou verificar se essas entidades diferem em seu desenho institucional, quanto à independência e à transparência; concluiu que há diferenças de desenho e procedimentos entre as agências, intra e inter-setores: "as instituições de infra-estrutura diferem entre si, da mesma forma que as instituições dos setores sociais".

As variáveis construídas por Gelis Filho foram as seguintes: para o parâmetro "independência", pessoa jurídica própria, fonte própria de recursos, mandato fixo dos dirigentes (pesam positivamente para o parâmetro "independência") e contrato de gestão (peso negativo); para o parâmetro "transparência", contrato de gestão, decisão colegiada, consulta pública e ouvidoria.

Tendo considerado como agências de infra-estrutura Anatel, Aneel, ANP, Antaq, ANTT e ANA, e como agências da área social ANS, Anvisa e Ancine, Gelis Filho conclui que as agências de infra-estrutura, em seu conjunto, são dotadas de maior independência do que as da área social, sendo a principal diferença a existência ou não de um contrato de gestão firmado com seu ministério supervisor. Quanto à transparência, o autor constata, em média, o mesmo grau de transparência para as agências dos dois setores.

Seria necessário estender a comparação às atribuições de cada agência, buscando caracterizar funções reguladoras e fiscalizadoras, ou ainda funções executivas, normativas e judicantes. A literatura sobre o tema no Brasil não se deteve sobre as diferenças, ainda que pouco marcadas, entre as agências reguladoras; centrou-se sobre a questão de seu grau de independência e os requisitos de accountability desses novos entes.

\section{Propostas para alterar o modelo}

No início de 2003, o novo governo anunciou sua intenção de promover ajustes no modelo; considerou que as agências gozavam de autonomia excessiva, que permitia inclusive ao ente regulador assumir a formulação da política para seu setor de atuação, inviabilizando seu controle por parte do Executivo. ${ }^{12} \mathrm{O}$ foco do debate foi a autonomia das agências, argumentando

\footnotetext{
12 Ver Pacheco (2005), sobre a evolução do tema durante o governo Lula, até o encaminhamento do projeto de lei ao Congresso, em abril de 2004, com propostas de alteração do modelo de agência reguladora.
} 
o governo que sua preocupação se dirigia aos déficits de responsabilização e de controle social.

No entanto, evidências mostraram que a discordância do governo era com o grau de autonomia das agências. Em janeiro de 2004, o governo demitiu o presidente da Anatel, baseando-se em argumentação jurídica elaborada a partir de brechas na legislação existente. ${ }^{13}$ A maioria dos especialistas se opôs às teses do governo, reafirmando a necessidade da autonomia para assegurar credibilidade regulatória. ${ }^{14}$

Durante a elaboração das propostas de mudança, o governo cogitou, em algum momento, promover uma diferenciação entre as agências existentes, segundo notícia divulgada no final de agosto de 2003:

O governo concluiu a minuta de dois projetos que alteram o funcionamento das agências reguladoras (...) O primeiro projeto muda as atribuições das agências, retirando, por exemplo, o seu poder de concessão. O segundo mexe na estrutura dos órgãos reguladores, determinando nova forma de contratação de pessoal e mudando a duração dos mandatos dos presidentes e dos diretores. Hoje, os mandatos têm duração diferente dentro da mesma agência (sic) e entre agências diferentes. A nova proposta prevê mandatos de quatro anos, coincidentes entre si e com o do presidente da República. ${ }^{15}$ Pelo projeto, há a possibilidade de perda do mandato de diretores e presidente. A estabilidade fica vinculada ao cumprimento de metas, cuja avaliação será feita por índices de desempenho que serão criados. Esse caso valeria apenas para as agências que regulam e fiscalizam setores onde há a possibilidade de monopólios. Estão nesse caso a Anatel, a Aneel, a ANP e a ANTT. Os diretores de outras agências como a ANA e a Ancine não teriam estabilidade no cargo. ${ }^{16}$

O tema da diferenciação das agências existentes, bem como a necessidade de limitar a setores específicos a criação de agências reguladoras, fez parte das análises e recomendações do relatório preparado por um grupo interministerial (Brasil, 2003). Em várias passagens, o relatório cita as análises

\footnotetext{
13 "Casa Civil acha que Lula pode trocar presidentes", Valor Econômico, 8 jan. 2004.

14 Sobre a questão da independência das agências reguladoras, ver Ferreira e Oliva (2004).

15 Quando divulgado o projeto de lei que manteve o instituto do mandato fixo para dirigentes das ARs, o subchefe de Ação Governamental da Casa Civil afirmou à imprensa que o projeto foi alterado no último momento, antes de seu envio ao Congresso, acatando a posição do ministro da Fazenda, contrário à eliminação do mandato fixo para os dirigentes (Valor Econômico, 14 abr. 2004).

16 "Projetos reduzem poderes de agências", Valor Online, 28 ago. 2003; grifos da autora.
} 
de Salgado (2003), com suas distinções entre "agências de governo" e "agências de Estado", considerando que:

deve restar claro que, não obstante a regulação econômica seja necessária sempre que existam falhas de mercado, de modo geral esta não é uma razão suficiente para a criação de uma agência, cuja necessidade tipicamente se dá apenas onde sejam necessários significativos investimentos irreversíveis (e.g., na infra-estrutura, como nas barragens, no tocante, por exemplo, à segurança da disponibilidade dos recursos hídricos).

(Brasil, 2003:7)

Nas recomendações, o relatório sugere que sejam definidos os setores que necessitam de agências reguladoras, justificando que "Esta definição conceitual é fundamental para evitar que corporações burocráticas ou grupos econômicos venham pressionar, futuramente, o governo para a instituição de agências em seus setores de atuação", "introduzindo custos desnecessários e improdutivos para o contribuinte" (Brasil, 2003:29, 7), mas abstém-se de propor uma alteração no estatuto das agências existentes.

Apesar de tais recomendações, os anteprojetos e o projeto de lei encaminhado em abril de 2004 ao Congresso não fizeram as distinções necessárias entre regulação e agência reguladora. As propostas encaminhadas tiveram o sentido oposto, o da uniformização das regras para todas as agências existentes; também não trataram da definição de regras para criação futura de novas agências. O governo, assim, perdeu uma oportunidade de corrigir equívocos da época da criação das agências, que levaram a estender o modelo do setor de infra-estrutura para as agências de regulação social.

O Projeto de Lei $\mathrm{n}$ o 3.337/04 confere estabilidade aos dirigentes durante a vigência de seus mandatos de quatro anos, deixando a cada novo presidente da República a faculdade de nomear novos dirigentes, no período compreendido entre o $7^{\mathrm{O}}$ e o $18^{\mathrm{o}}$ mês de mandato. Introduz o contrato de gestão para todas as agências, a ser supervisionado pelo ministro setorial, e condiciona o repasse de recursos orçamentários ao cumprimento de metas administrativas e de desempenho preestabelecidas. Cria a figura do ouvidor independente em cada agência, e disciplina o acompanhamento das consultas públicas realizadas pela agência por até três representantes de associa- 
ções de usuários, com despesas custeadas pela agência. ${ }^{17}$ Disciplina o processo decisório nas agências, estendendo a todas os mecanismos de decisão colegiada e de consulta pública.

O projeto de lei propõe a uniformização das regras para todas as agências, ignorando as diferenças entre as agências existentes. O governo perdeu assim uma oportunidade de corrigir equívocos da época da criação das agências, que levaram a estender o modelo do setor de infra-estrutura para as agências de regulação social.

O projeto de lei recebeu 137 emendas na Câmara dos Deputados; boa parte das emendas altera o dispositivo do contrato de gestão ou retorna às agências atribuições que o projeto de lei retorna para os respectivos ministérios. O relator do projeto, deputado Leonardo Picciani (PMDB-RJ), apresentou à Comissão Especial seu parecer em 29 de junho de 2004. Nem o substitutivo do relator nem as emendas propuseram alterar o projeto de lei no que se refere às distinções entre agências da área de infra-estrutura ou da área social; há emendas que propõem diferenciação das regras para uma agência específica, sem contudo caracterizar uma separação setorial nítida. O relator, em sua análise das 137 emendas, recusou várias delas alegando a necessidade de "uniformidade com procedimentos adotados em relação às demais agências".

\section{Referência: o modelo americano ${ }^{18}$}

Já salientamos as diferenças do caso brasileiro, em relação aos EUA; no Brasil, o formato de agências independentes representou delegação do Poder Executivo, protagonista de longa tradição na definição de políticas públicas e investimentos em infra-estrutura. Apesar disso, a experiência americana é tida como referência, considerando-se que os EUA têm mais de um século de atividades regulatórias.

As características dos sistemas político e institucional brasileiros diferem substancialmente daquelas presentes no caso americano. Pelo menos três importantes características indicam tais diferenças: a motivação para regular ("mais Estado" ou "menos governo"), a prestação privada ou estatal dos serviços públicos, a delegação a partir do Legislativo ou do Executivo.

Nos EUA, a criação de agências reguladoras foi impulsionada pelos reformadores do New Deal entre os anos 1930 e 1960. Representou simulta-

\footnotetext{
${ }^{17}$ A ouvidoria, a obrigatoriedade de consulta pública com a participação financiada de representantes de usuários, a obrigatoriedade de envio de relatórios ao Congresso e ao ministério setorial e o contrato de gestão vêm sendo anunciados pelo governo como mecanismos mais eficientes de controle social (ver Exposição de Motivos do projeto de lei - EM n $\mathrm{o}$ 12, Casa Civil).

18 Sobre a experiência americana em regulação, ver o excelente artigo de Sunstein, 2004.
} 
neamente o fortalecimento do Estado e o questionamento do common law anteriormente prevalecente (Sunstein, 2004). Os reformadores do New Deal propuseram agências autônomas, reunindo os três poderes até então separados pela Constituição; consideravam o common law como proteção dos direitos dos proprietários contra os riscos de intervenção indesejada do Estado. Comprometidos com a redistribuição da riqueza e com a criação de novos direitos sociais, os new dealers defendiam a criação de agências autônomas, visando aumentar o poder regulador do Executivo federal.

A partir dos anos 1930, o Congresso americano aprovou os novos entes, dotados de autonomia. Em seguida, o próprio Congresso buscou exercer seu controle sobre as atividades de regulação pela definição detalhada de procedimentos a serem seguidos por todas as agências - com a aprovação do Administrative Procedure Act (APA) em 1946.

Nos EUA, o período de maior expansão das agências reguladoras sucedeu à tradição do common law e à inexpressiva atuação do Estado nos mercados; lá, a defesa da regulação por meio de agências significou a defesa de maior atuação do Estado, em especial do Poder Executivo federal — também contrariando a tradição de sobrevalorização dos estados, em detrimento do poder federal. Os reformadores do New Deal posicionaram-se a favor de "mais Estado" para promover justiça social.

No Brasil, a criação das agências reguladoras independentes sucede uma longa tradição intervencionista do Estado na economia e nos mercados. Com um Estado vigoroso e a freqüente politização de decisões que afetam a lógica de setores de infra-estrutura, o debate em torno da regulação tende a valorizar a despolitização. A necessidade de autonomia para os entes reguladores visa criar credibilidade, junto aos investidores agora privados, de que regras não serão alteradas ou tarifas e preços não serão controlados segundo critérios políticos.

Assim, uma diferença fundamental a assinalar nas experiências dos EUA e Brasil, refere-se à natureza das relações entre regulação e poder do Estado. A autonomia das agências, para os new dealers, reforçava o poder do Estado, enquanto no Brasil, nos anos 1990, a concessão de independência às novas agências reguladoras buscou reduzir as incertezas, para o investidor, advindas do legado intervencionista do Estado.

A tradição americana é a de empresas privadas fornecedoras de utilities (energia, comunicações...); no Brasil são empresas estatais. Os quadros técnicos nas áreas de infra-estrutura vieram das empresas estatais, que praticavam melhores salários do que os ministérios correspondentes; a administração direta (os ministérios setoriais) nunca contou com uma burocracia técnica qualificada própria, tendo sempre recorrido ao empréstimo de quadros junto às empresas estatais, até que as privatizações colocaram um término a tais práticas. 
A literatura internacional vem discutindo a delegação em prol das agências como uma renúncia do legislador a seu poder de decisão, visando construir credibilidade regulatória por meio da obediência a regras e não pelo exercício discricionário (Melo, 2001). Essa autolimitação vem sendo analisada na literatura da escolha racional,

como estratégias de "pré-compromisso" de governantes em relação a escolhas intertemporais, ou seja, escolhas sobre situações futuras. Indivíduos racionais podem escolher limitar suas próprias escolhas no futuro antecipando seu próprio comportamento irracional ou miópico. Essa irracionalidade pode assumir a forma de paixões políticas ou de limitações na forma como os indivíduos fazem escolhas intertemporais. Os incentivos do mercado político levam os atores políticos a utilizarem uma alta taxa de desconto ao comparar benefícios futuros com benefícios presentes. Assim, em virtude da estrutura de incentivos em que operam, legisladores racionais são levados a preferir benefícios menores no curto prazo a benefícios maiores no longo prazo. Da mesma forma que Ulisses amarrou-se ao mastro do navio para não ser seduzido pelo canto das sereias, legisladores racionais podem escolher limitações ao exercício de sua vontade soberana (Elster, 1995). Ou seja, podem recorrer à delegação através de legislação que exige supermaiorias para ser alterada como um mecanismo de autodefesa, um pré-compromisso que assumem em relação ao futuro.

Tais análises enfatizam o processo parlamentar e a delegação de competências às agências reguladoras a partir do Poder Legislativo. Seria necessário desenvolvê-las para o caso da autolimitação do Poder Executivo - que talvez tenha menos motivação para amarrar-se, por contar com maior unidade de comando. Mesmo em governos de coalizão, o Executivo tem mais facilidade em estabelecer o comando único do que o Congresso, com centenas de parlamentares pertencentes a dezenas de diferentes partidos políticos.

Nos EUA, o questionamento em torno do grau de autonomia das agências reguladoras deu-se a partir dos anos 1960, tanto pelo Congresso quanto pelo Executivo e por decisões do Judiciário. ${ }^{19}$ As iniciativas visando maior controle das agências reguladoras pelo Executivo foram tomadas pelos presidentes Nixon, Ford e Carter. O presidente Reagan, interessado em promover a desregulação, passou a exercer um acompanhamento mais direto da atua-

19 Sobre a complexa evolução das posições do Judiciário ante as agências reguladoras, ver Mashaw, 2004. 
ção das agências, ao submetê-las à supervisão do Office of Management and Budget (OMB), por meio de decretos de 1981 e 1985 (Sunstein, 2004). Assim, a revisão do grau de autonomia concedido às agências americanas, defendida por governos de corte conservador, visou obter um recuo nas atividades de regulação (e na atuação do Estado), em prol de maiores liberdades ao mercado.

\section{As diferentes formas de controle}

A experiência americana de delegação foi acompanhada por um intenso debate sobre as formas de controle sobre tais entes autônomos - e as diversas finalidades políticas visadas. Por um lado, é importante distinguir diferentes naturezas de controle sobre as agências, entre eles "controle hierárquico" e "controle político". Por outro, podem ser desenhados distintos mecanismos de controle sobre as agências.

Quanto a este último aspecto, formou-se um consenso em torno da idéia de que há uma forma de "controle sem controladores diretos": "as agências estão sob controle mesmo não sendo controladas claramente por nenhum ator". Isso porque o controle tipo "patrulha de polícia" (o monitoramento sistemático exercido por parlamentares em relação a todo desvio potencial no funcionamento das agências - de custo elevado) teria sido eficazmente substituído pelo controle "alarme de incêndio" (monitoramento seletivo, de menor custo, sobre desvios denunciados pela base parlamentar dos congressistas). ${ }^{20}$

A necessária distinção entre controle hierárquico e controle político pode ajudar a definir os termos do debate. O controle hierárquico baseia-se na relação de autoridade que se estabelece entre o nomeador e o nomeado; é fortemente sustentado no paradigma clássico da burocracia, que pressupõe autoridade única e relações verticais de comando e controle. Tradicionalmente, o controle hierárquico é exercido pelo chefe do Poder Executivo, por meio do instituto da nomeação e demissão ad nutum dos ministros e demais dirigentes públicos. Segundo essa visão, autonomia das agências e controle pelo Executivo são antinômicos, pois o controle reside basicamente no poder de nomeação (e demissão) dos dirigentes da agência pelo chefe do Poder Executivo.

\footnotetext{
${ }^{20}$ McCubbins e Schwartz (1984) sistematizaram os conceitos e argumentos em torno das duas formas de controle - "patrulha de polícia" e "alarme de incêndio".
} 
Mas o significado de controle político é distinto, e decorre da exigência de accountability desses entes reguladores. O controle político implica a supervisão permanente exercida por múltiplos atores - e não apenas pelo Executivo. Para Sunstein (2004), o controle político resultaria da ação complementar e simultânea dos três poderes sobre a atuação das agências, sem retirar delas flexibilidade, especialização e autonomia; o autor faz referência a um controle agressivo exercido pelo presidente e pelo Congresso, simultâneo a um controle moderado exercido pelo Judiciário.

Expandindo as considerações de Sunstein sobre o controle político das agências reguladoras, poderíamos afirmar que, na ausência de controles simultâneos pelo Legislativo e pelo Judiciário, estaríamos diante do controle hierárquico pelo Executivo, o que não satisfaz às exigências de accountability daquelas agências. ${ }^{21}$ No Brasil, dados os padrões de fraca atuação do Legislativo e do Judiciário, os requisitos para alcançar accountability das agências parecem ser muito maiores do que aqueles introduzidos pelo projeto de lei enviado em abril de 2004 ao Congresso.

Ainda segundo o conceito elaborado por Sunstein, não haveria antinomia entre controle político e autonomia das agências - visto que o controle político não se dá via poder de demissão dos dirigentes, mas por outros mecanismos. Da mesma forma, a idéia de "controle social" não se confundiria nem substituiria o controle político sobre as agências.

O debate público em torno das agências reguladoras se beneficiará da precisão dos conceitos, ao distinguir as várias formas de controle e suas naturezas distintas - controle hierárquico, controle político e controle social.

\section{Algumas conclusões}

O desenho institucional das agências reguladoras no Brasil é um dos legados dos governos FHC. Ainda que não haja argumentos ou evidências, na literatura, para afirmar as intenções que então moveram o governo e seus principais atores, levando-os a desenhar instituições dotadas de autonomia em relação ao Executivo federal, é indiscutível que se tratou de inovação institucional, acompanhando a experiência internacional — pelo menos quanto à criação das agências de primeira geração, nas áreas de infra-estrutura onde o monopólio acabara de ser quebrado.

21 Para Sunstein (2004), a accountability das agências requer a atuação simultânea dos três poderes. 
O desenho original contemplou um formato único - com poucas variações - para agências atuando em áreas bastante diferentes, quanto à estrutura do mercado em seu setor de atuação, e com finalidades distintas.

O governo Lula afirmou sua intenção de reformar e aperfeiçoar o modelo institucional das ARs; para tanto, constituiu grupo interministerial, lançou dois anteprojetos de lei, submeteu-os a consulta pública, e acabou enviando ao Congresso projeto de lei que altera vários dos dispositivos das agências existentes. Não propôs mudanças, no entanto, nos formatos não distintos para agências atuando em setores da infra-estrutura e sociais. Atuou em sentido contrário, ao propor uniformizar todas as regras e procedimentos para o conjunto das ARs, argumentando na exposição de motivos que a uniformização das regras caracteriza um dos avanços da proposta.

O debate em torno do grau de autonomia das agências reguladoras, no Brasil, ainda não faz as distinções necessárias entre controle político e controle hierárquico, nem entre controle político e controle social. Tende a remeter autonomia à ausência de controle; tais características podem, no entanto, não ser antinômicas, desde que se avance na compreensão da natureza do "controle político". O controle hierárquico não garante responsabilização, e sim alinhamento; pode portanto não criar os mecanismos de accountability requeridos.

A tradição da cultura político-administrativa brasileira reside na opacidade e nos critérios tecnoburocráticos no processo de decisão dos agentes públicos. Os desdobramentos de tais traços na arena das instituições regulatórias, requerem maiores esforços empíricos. Mas é possível arriscar o argumento de que a criação das agências reguladoras no Brasil, sem distinguir formatos para as áreas de infra-estrutura e social, combinou características do entorno político-institucional com preferências, resistências e lógicas dos atores intragovernamentais, especialmente dentro do Executivo federal. Já a revisão do modelo, proposta pelo governo Lula, revela preferência pelo controle hierárquico, confundindo-o nos argumentos com controle social. Indistinção dos formatos organizacionais em um caso, indistinção das formas de controle no outro - provavelmente não será possível fazer avançar a regulação no Brasil sem que avance a reforma das demais instituições do aparelho do Estado.

\section{Referências bibliográficas}

ABRANCHES, S. Reforma regulatória: conceitos, experiências e recomendações. Revista do Serviço Público, v. 50, n. 2, p. 19-49, abr./jun. 1999. 
ABRUCIO, F.; LOUREIRO, M. R. (Orgs.). O Estado numa era de reformas: os anos FHC. Brasília: Seges-MP, 2002.

BRASIL. Casa Civil da Presidência da República, Câmara de Infra-estrutura e Câmara de Política Econômica. Análise e avaliação do papel das agências reguladoras no atual arranjo institucional brasileiro. Relatório Final do Grupo de Trabalho Interministerial. 2003.

BRASIL. Ministério da Administração Federal e Reforma do Estado. Plano diretor da reforma do aparelho do Estado. Brasília: Presidência da República, 1995.

BRESSER-PEREIRA, L. C. A reforma do Estado dos anos 90: lógica e mecanismos de controle. Cadernos Mare da Reforma do Estado, Brasília, v. 1, 1997.

Reforma do Estado para a cidadania - a reforma gerencial brasileira na perspectiva internacional. São Paulo: Editora 34; Brasília: Enap, 1998.

COSTA, V. M. F. A dinâmica institucional da reforma do Estado: um balanço do período FHC. In: ABRUCIO, F.; LOUREIRO, M. R. (Orgs.). O Estado numa era de reformas: os anos FHC. Brasília: Seges-MP, 2002.

ELSTER, J. Ulysses unbound: studies in rationality, precommitment, and constraints. Cambridge University Press, 2000.

FARIAS, P. C. L. de. Regulação e modelo de gestão. In: SEGES-MP. Balanço da Reforma do Estado no Brasil — a nova gestão pública. Brasília: Ministério do Planejamento, 2002. p. 95-101.

FERREIRA, F. M.; OLIVA, R. Delegação e controle político das agências reguladoras no Brasil. In: ENCONTRO ANUAL DA ANPAD, 28., Curitiba, 2004. Anais... Curitiba: Anpad, 2004.

GELIS FILHO, A. Análise comparativa do desenho normativo de instituições reguladoras do presente e do passado. In: ENCONTRO DE ADMINISTRAÇÃO PÚBLICA E GOVERNANÇA — ENAPG-ANPAD, 1., Rio de Janeiro, 2004. Anais... Rio de Janeiro: Enapg-Anpad, 2004.

MASHAW, J. Judicial review of administrative action: reflections on balancing political, managerial and legal accountability. In: CONFERENCIA ECONOMIC AND SOCIAL REGULATION, ACCOUNTABILITY AND DEMOCRACY, São Paulo, 2004. Anais... São Paulo: FGV e Cebrap, 2004.

MCCUBBINS, M.; SCHWARTZ, T. Police patrols vs. fire alarms. American Journal of Political Science, n. 28, p. 165-179, 1984.

MELO, M. A. B. C. Política regulatória: uma revisão da literatura. Revista Brasileira de Informação Bibliográfica em Ciências Sociais, n. 50, p. 7-44, 2000.

A política da ação regulatória: responsabilização, credibilidade e delegação. Revista Brasileira de Ciências Sociais, v. 116, n. 46, p. 55-68, 2001.

RaP Rio de Janeiro 40(4):523-43, Jul./Ago. 2006 
As agências regulatórias: gênese, desenho institucional e governança. In: ABRUCIO, F.; LOUREIRO, M. R. (Orgs.). O Estado numa era de reformas: os anos FHC. Brasília: Seges-MP, 2002.

MUELLER, B.; PEREIRA, C. Credibility and the design of regulatory agencies in Brazil. Brazilian Journal of Political Economy, v. 22, n. 3, p. 65-88, July/Sept. 2002.

PACHECO, R. S. El control de las agencias reguladoras en Brasil: ¿Ulises y las sirenas o Narciso? In: OSZLACK, O.; CUNILL, N. (Orgs.). La responsabilización en el Estado: aspectos teóricos y epistemológicos. Caracas: Clad, 2005. p. 215-238.

PECI, A.; CAVALCANTI, B. S. Reflexões sobre a autonomia do órgão regulador: análise das agências reguladoras estaduais. Revista de Administração Pública, Rio de Janeiro, v. 34, n. 5, p. 99-118, set./out. 2000.

PIRES, J. C. L.; PICCINI, M. S. A regulação dos setores de infra-estrutura no Brasil. In: GIAMBIAGI, F.; MOREIRA, M. M. (Orgs.). A economia brasileira nos anos 90. Rio de Janeiro: BNDES, 1999. p. 217-260.

SALGADO, L. H. Agências reguladoras na experiência brasileira: um panorama do atual desenho institucional. Rio de Janeiro: Ipea, 2003.(Texto para discussão n. 241).

SIQUEIRA, E. Telecomunicações. In: LAMOUNIER, B.; FIGUEIREDO, R. (Orgs.). A era FHC, um balanço. São Paulo: Cultura, 2002. p. 215-240.

SUNSTEIN, C. Constitucionalismo após o New Deal. In: STIGLER, G. J. (Coord.). Regulação econômica e democracia: o debate norte-americano. São Paulo: Editora 34, 2004. p. 131-242. 